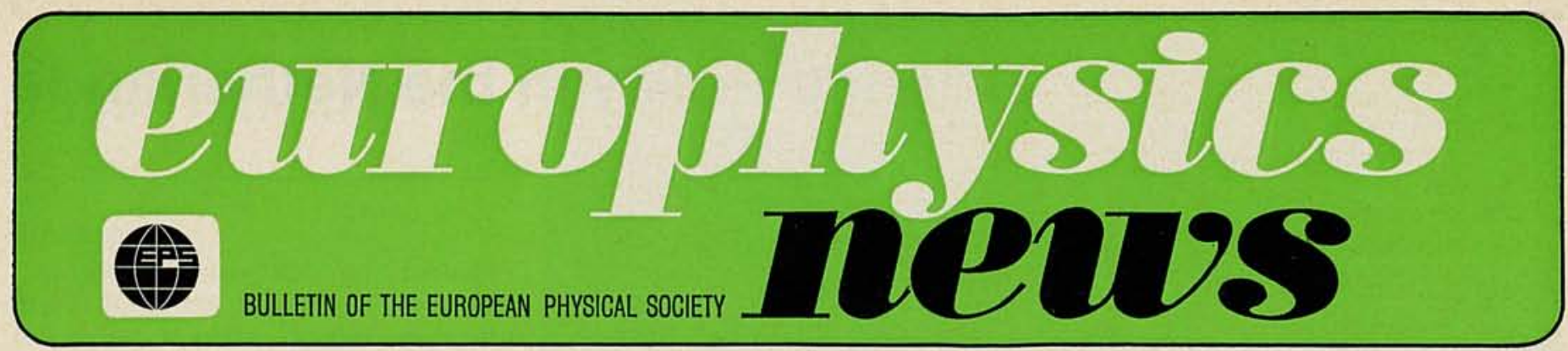

Volume 2 No. 2

\title{
The EPS and its Relations with Industry
}

\section{O. G. Folberth}

\section{The Purpose of Associate Membership}

Since its formation in September 1968 the European Physical Society has had as one of its principal objectives the establishment of strong relations with, on the one hand, the industrial organizations that are largely dependent on physics and, on the other, the entire community of European physicists. In order to reach this goal which is desirable from the human, scientific and technological points of view, the European Physical Society has made provisions for accepting industrial and commercial organizations as Associate Members.

Under this category of membership any organization (corporation, industrial establishment or research laboratory) directly interested in the activities of the European Physical Society but not qualified to join as a Member under Article $4 \mathrm{~b}$ of the Constitution will be considered for Associate Membership of the Society. This includes research laboratories, companies or corporations employing physicists, organizations involved in science education and other relevant bodies as outlined in Europhysics News No. 5 (September 1969) page 3 and No. 8 (March 1970) page 5 .

\section{Advisory Committee on Applied Physics and Physics in Industry}

The importance to be placed on the relations between physics and industry was underlined by the appointment in July 1969 of an Advisory Committee on Applied Physics and Physics in Industry charged specifically with the task of promoting the application of physics in industry, in other fields of science and in a great variety of human activities. Moreover, it is intended to encourage mutual contacts between physicists working in different branches of science and industry (see Europhysics News No. 8, March 1970, page 7).

One of the actions initiated by this Advisory Committee concerns an investigation of facilities and services which industrial and commercial organizations would find most valuable to be offered by the EPS to its Associate Members. It is, of course, clearly understood that the Associate Members themselves will ultimately decide upon the usefulness and value of these facilities and services. Nevertheless, the Advisory Committee would find it very helpful to learn from the community of European physicists what their opinions are in this vital matter.

\section{An Inquiry among Physicists}

Inserted at the centre of this issue we publish a questionnaire listing some of the services that are currently available or whose provision is being considered. On behalf of the Advisory Committee on Applied Physics and Physics in Industry, its Chairman, O.G. Folberth, appeals to everyone concerned to participate in this inquiry. It is desirable to obtain as many opinions as possible, and additional suggestions or comments that would help the Advisory Committee in its task will be most welcome.

Although the questionnaire is likely to be of particular interest to those concerned with applications and industry, the views of every physicist regardless of his affiliation to the EPS or a national society should prove of value in rendering this inquiry comprehensive. Furthermore, to enable significant conclusions to be reached a high proportion of the questionnaires must be returned to the EPS.

The answers received will be evaluated and processed by the Advisory Committee and a summary of the results will be published in Europhysics News. The few minutes spent in studying, completing and posting the questionnaire will greatly assist the European Physical Society in fulfilling one of its main aims. 
This article was published in Dutch in Nederlands Tijdschrift voor Natuurkunde in conjunction with the symposium on Science Policy organized by the Netherlands' Physical Society on 11 Septemiber 1970 in Amsterdam. J. Volger's summary covers the papers presented by J.H. Bannier, J.H. de Boer and A.G. van Vijfeijken. Papers read by C. le Pair and H.G. van Bueren at the symposium had been published extensively in Nederlands Tijdschrift voor Natuurkunde 36 (12), 3 September 1970.

\section{Background of the Symposium}

A number of reasons prompted The Netherlands' Physical Society to present this subject for public discussion. In the first few years after the war, physics made good headway, but now its growth has been cut back in favour of other sciences. During the last five years the budget of the Foundation for the Fundamental Research of Matter (FOM) has remained static. Physicists are becoming restless about the lack of clarity in science policy and the measure of secrecy that surrounds the making of decisions affecting the growth or restriction in some fields of research. Even the situation in the United States, where a drastic reduction in research budgets led to relatively high unemployment among physicists, is becoming relevant. To throw light on Dutch science policy seemed therefore both desirable and necessary, and the numerous attendance at the meeting clearly indicated the deep concern felt by Dutch physicists.

The contributions to the symposium backed up the interests and supported the point of view of Dutch physicists while urging moderation. It must now be clear to all that the questions discussed are closely linked with the complexities of economic policy. Progress in scientific research is bound to result from a clarification of the position and value of our science in its social context, enabling advisory and other decision-making bodies to stand on firmer ground.

\section{Summaries of Papers}

Examining the relations between science policy and physics J.H. Bannier, a former director of the Organization for Pure Research (ZWO) stated frankly that the government's science budget was a political matter, the reduction in money and manpower being due to competition with other government expenditure. Scientific programmes need thorough assessment, e.g. on the basis of Weinberg's criteria (A.M. Weinberg: Reflections on Big Science. MIT Press, 1967) :

- Is the field ripe for further research?

\section{Science Policy in the Netherlands}

\section{J. Volger}

- Is manpower available?

- What is the technological merit (direct benefit)?

- What is the scientific merit (indirect benefit)?

-What is the social significance?

The Netherlands' Advisory Board on Science Policy has tried to effect a more extensive integration of criteria assessing scientific activity with regard to its implications on

- the spiritual and cultural standard of living,

- the social conditions,

- the physical conditions,

- the economic potential, and

- the Dutch position in the international context.

But even these terms of reference will have to be further extended. The Board is of the opinion that the sciences must have some funds at their disposal and, with an assumed growth in the national income of $5 \%$ per annum, has been recommending an increase in the science budget of $15 \%$ for some years. This circumstance is the cause of difficulties, for the range of instruments used in the Organization for Pure Research (ZWO), indicated by The Netherlands' Advisory Board on Science Policy and including the system of differentiated percentage increases, has put physics in a predicament in view of the limiting budgetary fringe conditions. The ZWO would like to see the budget increased at the cost of those of the universities, but the government remains hesitant, since the question of the so-called secondary flow of funds (ZWO, FOM and others) is still being studied in its broader context. One advantage could ensue from these difficulties: the need for the discouragement of mediocrity.

J.H. de Boer, President of FOM discussed science policy within physics, surveying the activities of the FOM. After years of growth and prosperity there is now budgetary stagnation everywhere, i.e. recession, for each item of research the sophistication alone already requires a $5 \%$ increase per year. He considered Weinberg's criteria much more appropriate than those of the Advisory Board on Science Policy. Defining the scientific merit of a programme should be a matter for the whole community of physicists, who would also have to define the priorities. The technological merits are presumably also being considered within the FOM, although a little hesitantly. The assessment of the social merit should not be left solely to politicians. Although the physicists cannot survey and predict all implications, they must nevertheless give thought to and collaborate in the preparation of information and reports.

Technological forecasting was the subject of the paper by A.G. van Vijfeijken (Philips). He outlined a mode of thought that is at present gaining ground in the larger industrial laboratories. On the one hand, the functions which society at large requires to be fulfilled (e.g. communications, energy supply) are defined, on the other, there are the systems and the technical realizations which industry can offer for performing these functions. An enterprise will attempt to supply certain systems if this agrees with its objectives. The significance of technological forecasting can be seen in refining the motivation of research and development programmes. Another result is the more accurate prediction of a market development or of a political policy formulation, and also the closer consideration of the consequences (higher order effects) of an innovation, which necessitates the co-operation of those working in the $\gamma$-fields (fields outside the exact sciences).

\section{Forum Discussion}

Ample opportunities were provided for discussion. A forum was set up consisting of the symposium speakers as well as H.B.G. Casimir, member of the Advisory Board on Science Policy, and A.J. Piekaar, Director General of the Department of Education and Science; C.C. Jonker chaired the discussion. The main points concerning decision making in science policy are summarized below : 